\title{
Perceptual reality monitoring: Neural mechanisms dissociating imagination from reality
}

\author{
Nadine Dijkstra*a, Peter Kok ${ }^{a}$ \& Stephen M. Fleming ${ }^{a, b, c}$
}
a. Wellcome Centre for Human Neuroimaging, University College London, United Kingdom
b. Max Planck UCL Centre for Computational Psychiatry and Aging Research, University College London, United Kingdom
c. Department of Experimental Psychology, University College London, United Kingdom
* Corresponding author: Nadine Dijkstra (n.dijkstra@ucl.ac.uk)

Abstract. There is increasing evidence that imagination relies on similar neural mechanisms as externally triggered perception. This overlap presents a challenge for perceptual reality monitoring: deciding what is real and what is imagined. Here, we explore how perceptual reality monitoring might be implemented in the brain. We first describe sensory and cognitive factors that could dissociate imagery and perception and conclude that no single factor unambiguously signals whether an experience is internally or externally generated. We suggest that reality monitoring is implemented by higher-level cortical circuits that evaluate first-order sensory and cognitive factors to determine the source of sensory signals. According to this interpretation, perceptual reality monitoring shares core computations with metacognition. This multi-level architecture might explain several types of source confusion as well as dissociations between simply knowing whether something is real and actually experiencing it as real. We discuss avenues for future research to further our understanding of perceptual reality monitoring, an endeavour that has important implications for our understanding of clinical symptoms as well as general cognitive function.

\section{Keywords: perception, imagination, reality monitoring, metacognition}




\section{1. Introduction}

2 In order to function in complex environments, agents have evolved to move beyond stimulus-

3 triggered responses to actions guided by internal simulations (Mugan \& Maclver, 2020). Mental

4 simulation - the ability to imagine alternative scenarios to the one currently perceived - is a

5 cornerstone of human cognition and plays a key role in various cognitive processes such as memory,

6 planning and navigation (Barron, Auksztulewicz, \& Friston, 2020; Barron, Dolan, \& Behrens, 2013;

7 Epstein, 2008; Redish, 2016; Schacter et al., 2012; Zeidman, Mullally, \& Maguire, 2015). While

8 allowing for a vast increase in cognitive sophistication, the existence of stimulus-independent simulation poses a challenge to a nervous system: as soon as an agent has the capacity to engage in offline simulation, there is a need to keep track of what is imagined and what is real.

Research from different fields has repeatedly shown that internally generated imagination relies on similar neural machinery as stimulus-triggered perception (Fazekas, Nemeth, \& Overgaard, 2020). Overlap in sensory processing has been found between veridical perception and working memory (Christophel, Hebart, \& Haynes, 2012; Christophel, Klink, Spitzer, Roelfsema, \& Haynes, 2017; Harrison \& Tong, 2009), mental imagery (Dijkstra, Bosch, \& van Gerven, 2017; Lee, Kravitz, \& Baker, 2012; Naselaris, Olman, Stansbury, Ugurbil, \& Gallant, 2015; Reddy, Tsuchiya, \& Serre, 2010), dreaming (Horikawa, Tamaki, Miyawaki, \& Kamitani, 2013; Siclari et al., 2017) and hallucinations (Zmigrod, Garrison, Carr, \& Simons, 2016). The existence of such overlap emphasizes the challenge the brain faces in dissociating the two.

Perceptual reality monitoring - determining whether a current sensory experience reflects perception or imagination - might seem like a trivial process: after all, the phenomenological character of imagination seems so different from that of stimulus-triggered perception (KoenigRobert \& Pearson, 2021; Pearson \& Kosslyn, 2015). However, source confusions, wrongfully attributing an internally generated experience to an external source or vice versa, do happen. A clear example is hallucinations. During hallucinations an internally generated experience is erroneously evaluated as being real. Hallucinations form a key symptom in certain psychiatric disorders 
1 (McCarthy-Jones \& Longden, 2016) but are also prominent in the general population (Honig et al.,

2 1998; Sommer et al., 2010; Tien, 1991; Waters et al., 2014). Another example is dreams, during which we are generally unaware that what we experience is in fact not real (Corlett, Canavan, Nahum, Appah, \& Morgan, 2014 - with the notable exception of lucid dreaming, discussed in more detail below). Although less common, the reverse also happens: wrongfully attributing veridical perception to be the result of imagination. Various studies have shown that participants fail to notice the external presentation of objects when they are simultaneously imagining those objects, suggesting the external signal is mistaken for imagination (Finke, 1986; Okada \& Matsuoka, 1992; Reeves, 1981; Segal \& Fusella, 1970; Segal \& Glicksman, 1967; Segal \& Nathan, 1964). This effect is known as the Perky effect after its first description by Mary Cheves West Perky in 1910 (Perky, 1910). The different variants of perceptual source confusion are listed in Table 1.

Table 1. Perceptual source confusion. Sensory experience can be triggered internally or externally (true source) and can be inferred to have an internal or external source (attributed source). When the attributed source is different to the true source, this reflects a source confusion.

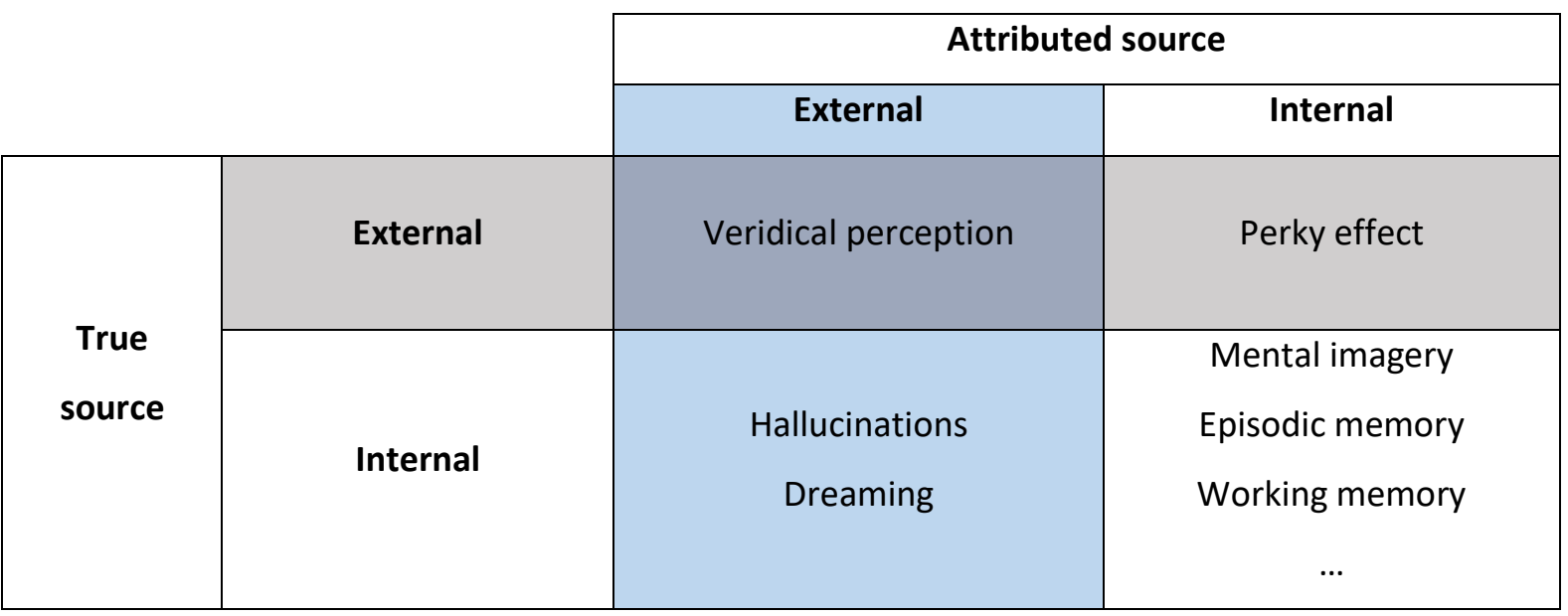

These examples demonstrate that determining whether a sensory experience has an external or internal source is a non-trivial process that is prone to error in both health and disease. In this article, we outline the neurocognitive mechanisms that might underlie perceptual reality monitoring - deciding in the moment whether a given perceptual experience reflects reality or imagination. We 
1 also discuss how it relates to a well-established framework for investigating reality monitoring of

2 memory - deciding after the fact whether an event really happened or was only imagined (Johnson

3 \& Raye, 1981; Simons, Garrison, \& Johnson, 2017), a process that can explain the existence of false memories (Robin, 2010; Robin \& Mahé, 2015). We first provide an overview of neurocognitive factors that might dissociate imagination and perception and that could be used as inputs to a perceptual source attribution system. In this paper, we define imagination as any sensory experience generated in the absence of the corresponding external signals. Next, we will discuss how these factors could be incorporated in a decision-making process that monitors the source of sensory experience. We then discuss differences between sensory and cognitive perceptual reality monitoring which are important for explaining phenomena such as lucid dreams. We finish by outlining an integrated framework for perceptual reality monitoring and suggest avenues for future research.

\section{What type of evidence can be used for perceptual source attribution?}

As outlined above, several lines of research have demonstrated that internally generated sensory experience arising from memory, imagery and dreaming relies on similar neural mechanisms as externally triggered perception (Dijkstra, Bosch, \& van Gerven, 2019; Horikawa et al., 2013; Pearson, 2019). The system therefore faces a challenge in dissociating imagination from real-world perception. In this section we discuss the differences between perception and imagination in terms of sensory signals and cognitive control. We suggest that these differences are used by a perceptual reality monitoring mechanism to determine the source of sensory experience and dissociate reality from imagination.

\subsection{Sensory strength and precision}

One of the most striking differences between perception and imagination is that the subjective experience of stimulus-triggered perception is generally much stronger and more detailed than that 
1 of internally generated imagery (Fig. 1). In line with this, it has been suggested that imagination is a

2 weak form of perception (Koenig-Robert \& Pearson, 2021; Pearson, Naselaris, Holmes, \& Kosslyn,

3 2015). This implies that one simple way to determine whether a given visual experience reflects

4 veridical perception or imagination would be to monitor its strength and detail: if the signal is strong and contains a high level of detail, it likely reflects external input. retroactively determining the source of memories (Johnson \& Raye, 1981; Simons et al., 2017): memories reflecting true events contain more details than memories based on imagined events. Indeed, it has been shown that more vivid imagery during memory encoding leads to more source attribution errors during recall: i.e. a higher likelihood of being misattributed as real (Markham \& Hynes, 1993; Stephan-Otto et al., 2017). Within the source monitoring framework, this is explained by the idea that more vivid imagery is more similar to perception (Johnson \& Raye, 1981; Simons et al., 2017).

If the strength of sensory experience also plays a role in perceptual reality monitoring, we would expect that more vivid imagery is more likely to lead to hallucinations. In line with this idea, it has been found that visual imagery vividness is elevated in people with schizophrenia (Sack, Van De Ven, Etschenberg, Schatz, \& Linden, 2005), and that in both Parkinson's and Alzheimer's disease, more vivid visual imagery is associated with an increased likelihood of experiencing visual hallucinations (El Haj et al., 2019; Shine et al., 2015). Similar effects have also been found within the auditory domain (Badcock \& Hugdahl, 2012; Slade, 1976). Furthermore, the Perky effect, mistaking veridical perception for imagination, only happens when the perceptual signal is presented around threshold; once the external signal becomes stronger, participants correctly attribute their sensory experience to perception (Okada \& Matsuoka, 1992; Segal \& Nathan, 1964).

The strength and precision of both imagined and perceived experiences is related to neural activation in sensory brain areas (Fazekas et al., 2020). The subjective visibility of perception as well as the vividness of imagery correlate positively with the strength of neural signals in visual cortex 
1 (Cui, Jeter, Yang, Montague, \& Eagleman, 2007; Fu et al., 2017; Ress \& Heeger, 2003; Tagliabue,

2 Mazzi, Bagattini, \& Savazzi, 2016). In general, however, neural activation in visual cortex during imagery is lower than during perception (Ganis, Thompson, \& Kosslyn, 2004; Ishai, Ungerleider, \& Haxby, 2000; Kosslyn, Ganis, \& Thompson, 2001; Winlove et al., 2018). Furthermore, the amount of information present in the signal, quantified as multivariate decoding accuracy, also tends to be

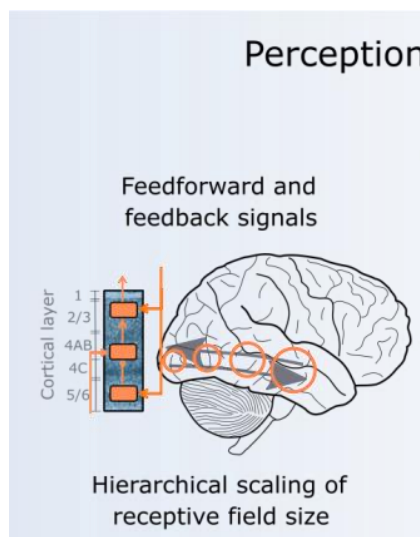

Figure 1. Differences in sensory processing between perception (left) and imagination (right). Veridical perception is generally experienced as clearer and more detailed compared to imagination, leading to the idea that imagery is like weak perception (Pearson et al., 2015). Neural signals in early sensory areas tend to be lower in amplitude (Ganis et al., 2004; Winlove et al., 2018) and code stimuli less precisely (Dijkstra, Mostert, de Lange, Bosch, \& van Gerven, 2018; Lee et al., 2012; Naselaris, Olman, Stansbury, Ugurbil, \& Gallant, 2015b; Reddy et al., 2010) during imagination compared to perception. This is likely due to the fact that imagined signals originate from high-level areas with large receptive fields, leading to top-down influences of lower spatial resolution which terminate at the deep and superficial layers of early sensory areas (Lawrence et al., 2018; Van Kerkoerle, Self, \& Roelfsema, 2017; Aitken et al., 2020). In contrast, signals during perception originate from the high-resolution retina and enter the cortex via the middle layers of the early visual cortex, leading to a hierarchical organization in receptive field size from low to high-level visual areas. Landscape image: link, brain image: link.
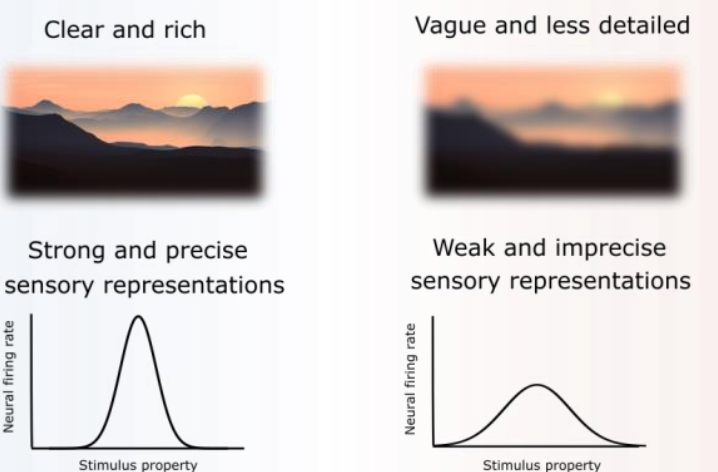

Large receptive fields in all visual areas

The different properties of externally and internally generated sensory representations can be explained by a reversal of information flow during imagination compared to perception (Dijkstra, Ambrogioni, Vidaurre, \& van Gerven, 2020; Linde-Domingo, Treder, Kerren, \& Wimber, 2019). 
1 During normal perception, neural activation is ultimately triggered by external signals from the retina, entering the cortex via the middle layer of V1 and then progressing up the visual hierarchy via feedforward connections (Felleman \& Van Essen, 1991; Fracasso, Petridou, \& Dumoulin, 2016; Kok, Bains, Van Mourik, Norris, \& De Lange, 2016; Lawrence et al., 2018) (Fig. 1). In contrast, signals during imagery have been shown to be generated in high-level visual areas and flow down the visual hierarchy via feedback connections, terminating in the deep layers of V1 (Al-Tahan \& Mohsenzadeh, 2020; Bergmann, Morgan, \& Muckli, 2019; Dijkstra, Zeidman, Ondobaka, van Gerven, \& Friston, 2017; Fig 1).

Feedforward connections strongly drive neural activity, i.e. causing downstream neurons to fire action potentials, whereas feedback connections generally modulate neural activity, changing existing firing rates via gain control, but usually without driving neurons to fire action potentials in isolation (Bastos et al., 2012; Crick \& Koch, 1998; Klink, Dagnino, Gariel-Mathis, \& Roelfsema, 2017; Koenig-Robert \& Pearson, 2021; Larkum et al., 2013; but see e.g. Hupé et al, 1998). This explains why neural activation during perception is stronger than during imagination. Furthermore, two recent studies showed that compared to stimulus-triggered perception, population receptive fields (pRFs) are larger during memory (Favila, Kuhl, \& Winawer, 2020) and imagery (Breedlove, St-Yves, Olman, \& Naselaris, 2020). Instead of increasing in size across increasing levels of the visual hierarchy as they do during perception (Gattass et al., 2005; Fig. 1), during imagery and memory pRFs are as large in lower-level visual areas as they are in higher-level areas (Breedlove et al., 2020; Favila et al., 2019; Fig. 1). This can be explained by the idea that the precision in higher-level areas serves as an upper limit on the precision of internally generated representations, such that these are necessarily less detailed than their feedforward counterparts (Breedlove et al., 2020; Favila, Kuhl, \& Winawer, 2020). Together, this suggests that differences in sensory strength and precision between veridical perception and internally generated imagination are due to differences in the origin of the signals and the hierarchical organisation of sensory systems in the brain. Furthermore, this view predicts 
1 resolution feedforward signals enter and low-resolution feedback signals terminate. Indeed, overlap

2 in neural representations of imagined and perceived stimuli is most pronounced in high-level visual

3 areas (Dijkstra, Bosch, \& van Gerven, 2019; Ishai et al., 2000; Lee et al., 2012). Moreover, the vividness of visual imagery has been shown to be predominantly related to activation in low-level visual areas (Albers, Kok, Toni, Dijkerman, \& De Lange, 2013; Cui et al., 2007; S.-H. Lee et al., 2012) , as well as the strength of top-down connections to early visual areas within the visual system (Dijkstra, Zeidman, Ondobaka, Van Gerven, \& Friston, 2017)

Taken together, these findings reveal that the natural organisation of sensory systems

\subsection{Cognitive control and predictability}

Sensory strength is not the only factor that determines whether something is experienced as real. This is demonstrated by the existence of extremely strong mental imagery (referred to as 'hyperphantasia'), that is still experienced as imagined rather than real (Zeman et al., 2020) - as well as the existence of very weak externally triggered visual experience which is still correctly attributed to perception. A distinct factor that may modulate source attribution in these cases is cognitive control: sensory experience during imagination can be voluntarily generated whereas perception is triggered by the external appearance of stimuli (Waters, Barnby, \& Blom, 2021).

Imagination can make sensory information that is currently not present in the environment available to the system in order to execute some cognitive task (Kosslyn et al., 2001). For example, when shopping for new furniture, you might imagine what your living room looks like in order to 
decide which new couch to buy. In this case, sensory information is voluntarily activated and can be controlled to a high degree: you can easily change the colour, shape and position of the couch in the living room to decide which is the best match. In contrast, perception is mostly determined by what comes into the senses and the amount of control we have over its content is limited (Fig. 2).

Cognitive control has also been identified as an important factor in reality monitoring of memories (Johnson, Hashtroudi, \& Lindsay, 1993; Johnson \& Raye, 1981). In one study, participants were instructed during a recall phase to discriminate whether words had been self-generated or presented by the experimenter (Johnson, Raye, Foley, \& Foley, 1981). When the self-generation process was made more automatic, for example by giving the first letter of a word, participants were more likely to say it was presented by the experimenter. In contrast, when the self-generated words involved more cognitive operations, these were later more likely to be classified as self-generated (Johnson et al., 1981). Furthermore, the absence of control is a key aspect of hallucinations (Badcock, Waters, Maybery, \& Michie, 2005; David, 2004; Waters, Badcock, Michie, \& Maybery, 2006; Waters et al., 2014), suggesting that cognitive control is also an important factor in perceptual reality monitoring.

One hypothesis would therefore be that internally generated experience is associated with stronger cognitive control compared to externally driven perception. The neural mechanisms of cognitive control have long been thought to depend on the frontal cortex (Badre \& Nee, 2018; Miller, 2000; Miller \& Cohen, 2001; Ridderinkhof, Ullsperger, Crone, \& Nieuwenhuis, 2004). In line with this proposal, studies contrasting activation during imagery and perception tend to find stronger activation in frontal areas during imagery (Dijkstra et al., 2017; Dijkstra et al., 2019; Ishai, Haxby, \& Ungerleider, 2002; Ishai, Ungerleider, \& Haxby, 2000a; Kosslyn et al., 2001) as well as stronger connectivity from frontal to sensory areas (Dentico et al., 2014; Dijkstra, Zeidman, Ondobaka, Van Gerven, \& Friston, 2017; Mechelli et al., 2004). The strength of top-down control could then be another factor that informs perceptual reality monitoring, in addition to sensory 
Perception

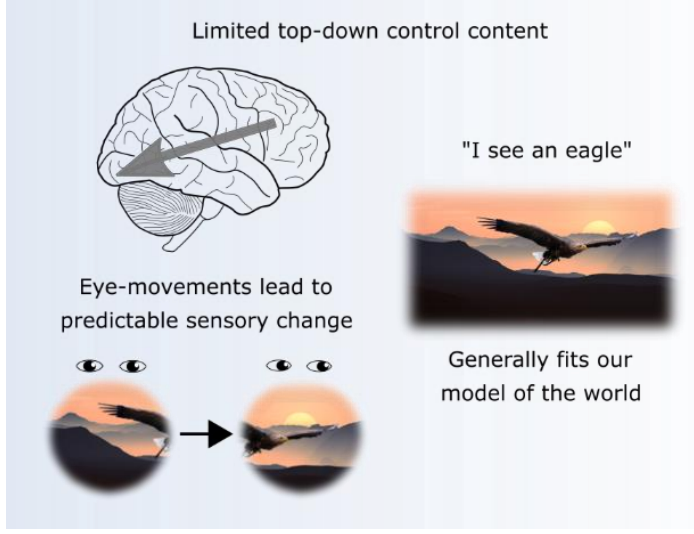

Imagination

Strong top-down control content

"I want to see a pink elephant"
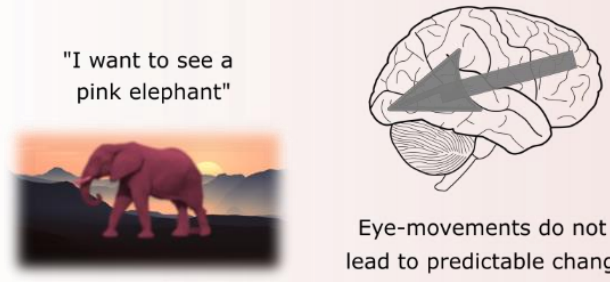

Eye-movements do not lead to predictable change

Does not have to fit our model of the world

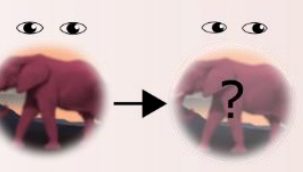

Figure 2. Differences in cognitive control between perception (left) and imagination (right). The content of perception is under diminished voluntary control compared to the content of imagination: perception is mostly driven by what happens in the environment whereas the content of imagination is largely voluntarily determined, making its content more predictable. An alternative perspective is that the content of perception generally fits with our internal model of the world, which is not the case for imagery, making imagery less predictable. Furthermore, perceptual content can be manipulated by changing the focus of attention or moving the eyes, which leads to predictable changes in sensory signal. In contrast, while eye-movements appear to play a role in imagination, they do not lead to predictable changes in sensory input. Eagle picture: link, elephant picture: link

However, top-down control of sensory representations is also an integral part of perception (Fig. 2).

We pay attention to different parts of our visual input depending on our current goals. There is evidence that these attentional operations during perception may even be implemented via the same top-down mechanisms that underlie imagery (Dijkstra, Zeidman, et al., 2017; Gazzaley \& Nobre, 2012; Xie, Kaiser, \& Cichy, 2020). Furthermore, not all internally generated sensory experiences that are outside of voluntary control are incorrectly attributed to perception. For example, the rapid stream of mental images associated with mind-wandering or intrusive images associated with post-traumatic stress disorder are triggered automatically, but are still correctly classified as internally generated (Fazekas, 2021; Pearson, 2014).

Therefore, while cognitive control seems to be higher during internally generated experience, it is not enhanced in all forms of imagination and it also plays an important role in 
1 perception. This implies that the level of cognitive control cannot conclusively dissociate internally

2 from externally generated experience. Besides control, one other important cognitive aspect of the self-generated nature of imagination is that imagined sensory signals are highly predictable; after all, they are generated by an internal model (Fletcher \& Frith, 2009; Frith, Blakemore, \& Wolpert, 2000; Griffin \& Fletcher, 2017; Sterzer et al., 2018). This has led to the proposal that a sense of agency, or ownership, of our actions is partly determined by how predictable they are (Haggard, 2017). Accordingly, perceptual reality monitoring might then be accomplished by evaluating how predictable sensory activation is, with more predictable activation being attributed to an internal source.

However, in contrast to internally versus externally triggered actions (Haggard, 2017), externally generated sensory signals are in some ways more predictable than internally triggered sensations. This is because, contrary to imagination, externally triggered sensations are spatiotemporally smooth (van Bergen \& Jehee, 2019). This means that the spatial configuration of sensory input tends to change little from one moment to the next. Put differently, in contrast to what can happen in our imagination, objects in the real world generally do not pop in and out of existence. Furthermore, external sensations tend to obey our model of the external world: they follow the rules of physics and are generally in line with what we expect based on the overall context (Press, Kok, \& Yon, 2020). Together, these considerations suggest an alternative hypothesis, namely, that the larger the prediction error associated with a sensory signal, the higher the probability that it reflects an internal source, i.e. does not reflect veridical perception (Drori, Bar-Tal, Stern, Zvilichovsky, \& Salomon, 2020). This hypothesis would predict that if a sensory signal appears suddenly and is incongruent with the current context we are more likely to think it is imagined. Indeed, the sudden appearance of a polar bear in your living room would likely make you question whether it was real (hopefully after hiding first, just in case). On the other hand, the content of our imagery is to some extent also constrained by our internal model of the world: while we can combine known features in novel ways in our imagination (e.g. a pink polar bear) we are unable to 
1 imagine features we have never seen before (e.g. an ultraviolet polar bear). Our imagery also does

2 generally follow the context of our internal world and stream of thoughts, and its content is therefore likely to be somewhat predictable over time.

A final possible cue for reality monitoring might be how externally versus internally generated signals are altered by (eye) movements (Seth, 2014). When we move our eyes, the objects in the external world tend to remain in the same location, causing the associated visual signals to shift on our retinas. In turn, downstream sensory processing is influenced by the changes in sensory input associated with (eye) movements: if an eye-movement causes an external object to move from the left side of the visual field to the right side, its associated sensory representation is re-mapped from the right to the left hemifield in the brain. In contrast, signals coming from our sensory apparatus itself, such as the shadows caused by blood vessels on the surface of the retina, or scotomas, move along with our eye movements (i.e., are retinally invariant). Therefore, retinal invariance could provide a cue as to whether signals originate from the outside world. According to the perceptual scotoma hypothesis, this mechanism can explain motion induced blindness - the perceptual disappearance of attended, stationary stimuli when set against a moving background (New \& Scholl, 2008, 2018). The idea is that, in the context of globally changing signals, objects that remain stationary are assumed not to represent the external world and can therefore be discarded (New \& Scholl, 2008, 2018).

However, while retinal invariance might prove a useful cue to the absence of external input, the presence of eye gaze-contingent effects is not a reliable cue to its presence. Perhaps surprisingly, mental imagery is often also accompanied by content-specific eye-movements (Gurtner, Hartmann, \& Mast, 2021; Martarelli \& Mast, 2021; Mast \& Kosslyn, 2002) and while the changes in external input associated with eye-movements should not influence purely internally generated sensory representations, recent findings have shown that internally generated representations are also remapped during eye-movements (Brincat et al., 2021). This means that the way (eye) movements alter sensory processing might be similar during perception and imagery and unless a reality 
monitoring system has direct access to what is happening at the retina, this might not tell apart imagination and reality.

In conclusion, top-down control and predictability seem to be different for internally generated versus externally driven sensory experience (Fig. 2). Top-down control is generally higher during imagination compared to perception and this generative nature of imagined sensory signals makes them in some ways more predictable. Furthermore, loss of control and unexpectedness are defining features of hallucinations. This suggests that source confusions might happen when control of internally generated experience is lost, making it feel less predictable, or when externally driven perception erroneously seems to be under voluntary control. However, the content of externally driven perception is to some extent also under top-down control, for example via (covert) attention and action. This, together with the fact that external signals are constrained by the physics of the external world, makes them in some ways more predictable than imagination. Finally, (eye) movements lead to predictable changes in externally generated signals whereas self-generated signals are typically retinally invariant, suggesting this might be a way to dissociate imagination and reality. However, recent evidence suggests that sensory processing of internally generated signals might be altered by eye movements in a similar way to perceived signals. Therefore, while cognitive control and predictability are clearly important in dissociating imagination from reality, it remains unclear exactly how they might each inform perceptual source attributions.

\section{How is a perceptual source decision made?}

Summarizing the evidence above, compared to externally triggered perception, internally generated sensory experience seems to be weaker and less detailed (Fig. 1), under more cognitive control, and less constrained by our model of the world (Fig. 2). However, none of these features exhaustively separates externally from internally generated sensory experiences. This suggests the need for a reality monitoring mechanism that integrates information about sensory experience to make source attributions. In the following section we first discuss possible neural substrates of such a mechanism 
1 and how it relates to metacognition. Then, we will highlight a distinction between different levels of reality monitoring which is necessary to explain phenomena such as lucid dreams.

\subsection{Higher-order perceptual reality monitoring}

Two recent accounts suggest that deciding whether sensory signals represent reality or imagination is achieved via a higher-order inferential process (Gershman, 2019; Lau, 2019; Fig. 3). One computational framework proposes that reality monitoring is important for learning efficient generative models (Gershman, 2019). In recent advances in artificial intelligence and machine learning, architectures known as generative adversarial networks (GANs) learn internal or generative models of the world with the aid of a discriminator that dissociates input from simulations. In this context, reality monitoring as achieved by such a discriminator is an inherent part of efficient perceptual learning (Gershman, 2019). Another, complementary, account proposes a tight link between reality monitoring and metacognition. In brief, the idea is that metacognitive processes that evaluate confidence in our memories or perceptions - whether they are an accurate reflection of the external world - may also be co-opted to distinguish between reality and imagination. According to this view, perceptual reality monitoring is implemented within a multi-level system where higher, metacognitive levels evaluate the precision or reliability of lower, sensory levels. In Lau's perceptual reality monitoring account of consciousness, for instance, such mechanisms infer whether current sensory signals accurately reflect the external world, our internal imagination, or noise (Lau, 2019).

This latter model implies a tight coupling between perceptual reality monitoring and metacognition, such that we would expect deficits in metacognition to be associated with deficits in reality monitoring and vice versa. In line with this hypothesis, schizophrenia is associated with impaired metacognition about memory (Moritz, Woodward, Jelinek, \& Klinge, 2008; Steffen Moritz, Woodward, \& Rodriguez-Raecke, 2006), as well as generally decreased metacognitive functioning 
1 between patients with schizophrenia and healthy controls (Faivre et al., 2019), suggesting potential

2 differences between reality monitoring and metacognition. However, this study did not report

3 whether and to what extent the patients also experienced visual hallucinations, which may be crucial

4 since the above accounts predict that metacognitive deficits would be specifically present in patients

5 suffering from hallucinations.

Furthermore, within such hierarchical architectures, errors in perceptual reality monitoring might be caused by different factors (Fig. 3). First, source confusions could arise due to disturbances in specific first-order sensory or cognitive processes that generally separate perception and imagination. For instance, hallucinations may be related to very strong internally generated sensory signals and/or weak cognitive control signals. Conversely, source confusions could also arise from deficits in the reality monitoring process itself, which performs a source inference on the basis of the strength of these sensory and cognitive control signals (Fig. 3). Indeed, such a multi-factor explanation has been suggested to explain differences in clinical versus non-clinical hallucinations, where non-clinical hallucinations might be solely due to hyperactivation of sensory systems with a generally intact reality monitoring system, whereas hallucinations in schizophrenia might further be associated with malfunctioning reality monitoring (Simons et al., 2017). Deficits at these different levels might also lead to dissociable effects on first-order (e.g. perceptual, $d^{\prime}$ ) versus second-order (metacognitive, meta-d') performance respectively, which have often been confounded in previous studies (Fleming \& Lau, 2014). Future studies should investigate how deficits in reality monitoring relate to different levels of perceptual and metacognitive processing. 
True source: internal
Accurate

source attribution

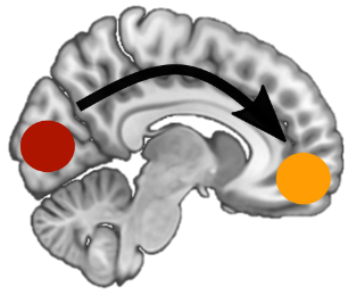

Sensory signal

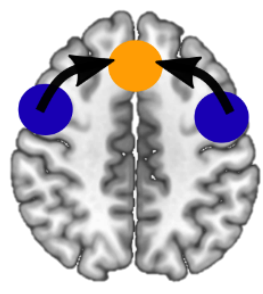

Cognitive control
Source attribution due to sensory hyperactivity

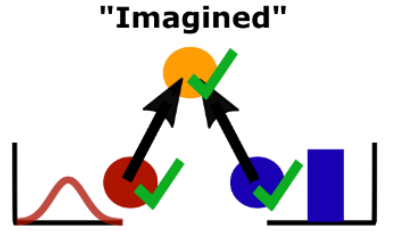

Source confusion

"Real"

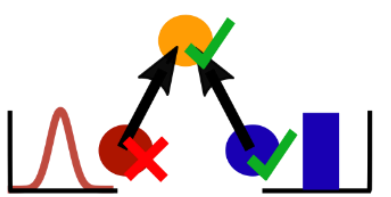

Source confusion due to loss of control

"Real"

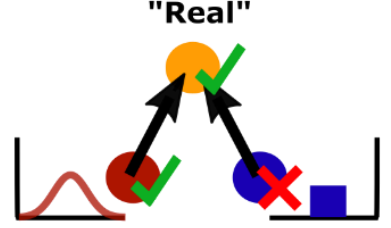

Source confusion due to misattribution

"Real"

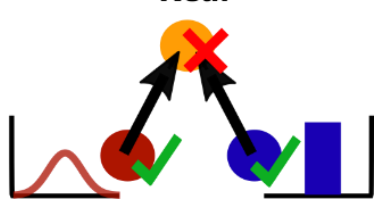

Figure 3. Potential neural mechanisms for perceptual reality monitoring. The anterior medial prefrontal cortex (amPFC; yellow circle) evaluates sensory (Fig. 1; red circle) and cognitive control (Fig. 2; blue circles) aspects of perception and imagination in order to make a source attribution. For accurate source attribution, the neural basis of first-order perceptual and cognitive processes that distinguish perception and imagination, and the workings of a second-order source attribution process, should both be intact. Source confusions can therefore arise from different combinations of deficits as illustrated by the examples on the right.

In line with the idea of a higher-order system contributing to reality monitoring, previous research has suggested a unique role for the anterior medial prefrontal cortex (amPFC, Brodmann's area 10) in determining the source of memories. The amPFC has been consistently shown to differentiate between the retrieval of internal versus external aspects of memories (Simons et al., 2017); for example, determining whether an object was previously perceived or imagined (Kensinger \& Schacter, 2006). Activation in this area correlates negatively with the tendency to misattribute imagined memories as real (Simons, Davis, Gilbert, Frith, \& Burgess, 2006). Furthermore, variation in the size of the paracingulate sulcus (PCS), a cortical fold located within the amPFC, correlates with performance in reality monitoring tasks within the healthy population (Buda, Fornito, Bergström, \& Simons, 2011), such that a larger amPFC surface is associated with better reality monitoring. Similar evidence that the amPFC may be important for perceptual reality monitoring comes from studies on schizophrenia. Errors in source attribution of memory are greater in patients with schizophrenia who also experience hallucinations compared to patients without hallucinations (Seal, 
1 with schizophrenia from healthy controls (Fornito et al., 2006) and also dissociates patients who experience hallucinations from patients who do not (Garrison et al., 2015). However, the relationship between PCS morphology and hallucinations might not generalize to non-clinical populations (Garrison, Fernyhough, McCarthy-Jones, Simons, \& Sommer, 2019). Functionally, decreases in amPFC activity are associated with more severe hallucinations in schizophrenia (Yanagi et al., 2020) and several studies have found decreased connectivity between auditory cortex and amPFC in patients with schizophrenia who hear voices (Mechelli et al., 2007; Wang, Metzak, \& Woodward, 2011) as well as reduced global connectivity between amPFC and the rest of the brain in non-clinical voice-hearers (Lin et al., 2020). Furthermore, one study found that both clinical and nonclinical participants who experienced hallucinations in daily life were less likely to engage the amPFC during a detection task compared to clinical and non-clinical participants who did not experience hallucinations (Powers, Mathys, \& Corlett, 2017), indicating its importance for accurate perceptual source attributions.

A broader network of prefrontal subregions may also contribute to perceptual reality monitoring. For instance, in the primate brain, signals in lateral prefrontal cortex have been shown to differentiate memorized versus perceived stimuli (Mendoza-Halliday \& Martinez-Trujillo, 2017). Furthermore, metacognitive evaluation of sensory signals has repeatedly been shown to engage the medial and lateral anterior PFC, both during perception and imagination (Bang, Ershadmanesh, Nili, \& Fleming, 2020; Bang \& Fleming, 2018; Cui et al., 2007; Dijkstra, Bosch, et al., 2017; Fleming, Van Der Putten, \& Daw, 2018; Gherman \& Philiastides, 2018; Mazor, Friston \& Fleming, 2020; Morales, Lau, \& Fleming, 2018; Motes, Malach, \& Kozhevnikov, 2008).

Taken together, convergent evidence suggests that perceptual reality monitoring might be achieved by higher-order circuits centred on anterior medial prefrontal cortex evaluating low-level sensory and cognitive aspects of a perceptual experience (Fig. 3). According to this view, perceptual reality monitoring and metacognition are highly related and share common neural mechanisms. 
1 Furthermore, according to this account, errors in perceptual reality monitoring can arise from

2 deficits in either first-order processes, second-order processes, or both. In the next section, we discuss how interactions between these different levels could further explain various types of source confusions.

\subsection{Recurrence between monitoring and sensory processing}

It is now commonly accepted that perception does not only rely on feedforward processing but that perceptual inference is performed iteratively via recurrence between different levels of processing hierarchies (Bastos et al., 2012; Friston, 2005; Hochstein \& Ahissar, 2002; Lee \& Mumford, 2003). Within this context, higher-level inferences are fed back to lower-levels to regulate low-level processing. In line with this, there is now ample evidence that prior knowledge influences our perception (Aitken, Turner, \& Kok, 2020; de Lange, Heilbron, \& Kok, 2018; Kersten, Mamassian, \& Yuille, 2004). In contrast, the sketch of reality monitoring outlined above is unidirectional: higherorder frontal areas collect information in a feedforward manner to decide whether a sensory experience is real or imagined. One important question is whether metacognitive processes involved in source attribution are part of a broader recurrent network that exerts top-down influences on perception.

There is some evidence for recurrent interactions between metacognitive judgements and perceptual processing. Two recent studies showed that confidence in a perceptual decision biased subsequent low-level sensory processing in favour of that decision (Balsdon, Wyart, \& Mamassian, 2020; Rollwage et al., 2020). Furthermore, with respect to reality monitoring, a recent study showed that cultural beliefs about seeing spirits and gods influenced the frequency at which these events were experienced (Luhrmann et al., 2021). Using a cross-cultural, interdisciplinary approach, this study found that people who believed that such visions had religious significance, and that the mind was permeable to the world, were more likely to experience such hallucinations (Luhrmann et al., 
1 2021). These findings suggest that higher-order beliefs about the source of sensory signals can in

2 turn influence sensory processing.

3 This view suggests that during reality monitoring, the output of a high-level source attribution is sent back to sensory areas to alter sensory processing in an iterative, recurrent loop. One consequence of such an architecture could be that sensory signals that are initially inferred to accurately reflect the external world are amplified whereas signals that are inferred to reflect noise or imagination might be dampened. This could explain the Perky effect where, during imagination, signals that would have usually been strong enough to be perceived are missed (Okada \& Matsuoka, 1992; Perky, 1910; Segal \& Gordon, 1969; Whitford et al., 2017). In this case, the belief that one is imagining would dampen sensory activity, leading to lower detection rates. Furthermore, a recent study showed that people have the tendency to remember previously seen scenes as more vivid than they actually were during encoding, suggesting that the sensory signals were amplified after encoding (Rivera-Aparicio, Yu, \& Firestone, 2021).

A recurrent architecture also implies that imbalances at any level of the hierarchy can have large effects throughout the network. For example, a minor dysfunction in a higher-level monitoring system might bias source attribution towards reality, leading to amplification of sensory signals (e.g. sensory hyperactivity, Fazekas, 2021) which are in turn more readily attributed as real in the next iteration (Jardri \& Denève, 2013). In line with this, hallucinations and psychoses have been explained as imbalances at different levels within a hierarchical system (Corlett et al., 2019; Fletcher \& Frith, 2009; Wengler, Goldberg, Chahine, \& Horga, 2020). Indeed, several studies have found differences in hierarchical perceptual inference to be linked to changes in reality monitoring (Haarsma et al., 2020; Powers lii, Kelley, \& Corlett, 2016; Sterzer et al., 2018). To characterize the recurrent nature of reality monitoring, future research should investigate whether source attribution judgements themselves dynamically influence the strength of sensory signals. 
1 Generally, sensory experiences that are attributed to an internal source (e.g. working memory, imagery, mind-wandering) also do not feel real; their phenomenology is very different from veridical perception. In those instances, beliefs about the reality of the experience are in line with its phenomenology. However, this is not always the case. For example, drug-induced hallucinations might feel very real even though the person experiencing them knows they are a direct effect of the drug they took and do not reflect external reality. Another striking example is lucid dreaming during which a dreaming person can suddenly realize that they are dreaming and that their current sensory experience therefore is not real (Corlett et al., 2014; Konkoly et al., 2021) (for more examples, see

Table 2). These cases show that there are situations in which a belief about the source of a sensory signal and its effect on sensory experience are dissociable.

Table 2. Perceptual versus cognitive source attribution (irrespective of true source). Source attributions can be made at two distinct levels: whether something is experienced as real or imagined (experience) and whether something is believed to be real or imagined (belief). Usually, these two levels are in line with each other, but in some circumstances, they can be dissociated. 1. Foote, Smolin, Kaplan, Legatt, \& Lipschitz, 2006

\begin{tabular}{|c|c|c|c|}
\hline & \multicolumn{2}{|c|}{ Belief } \\
\hline & & External & Internal \\
\hline \multirow{2}{*}{ Experience } & External & $\begin{array}{l}\text { Veridical perception } \\
\text { Hallucinations without insight } \\
\text { Non-lucid dreaming }\end{array}$ & $\begin{array}{l}\text { Hallucinations with insight } \\
\text { Lucid dreaming } \\
\text { Projector synaesthesia } \\
\text { Some visual illusions }\end{array}$ \\
\hline & Internal & $\begin{array}{l}\text { TMS induced phosphenes } \\
\text { Dissociative disorders }{ }^{1}\end{array}$ & $\begin{array}{c}\text { Mental imagery } \\
\text { Memory recall } \\
\text { Working memory } \\
\text { Associator synaesthesia }\end{array}$ \\
\hline
\end{tabular}

The existence of a dissociation between reality beliefs and reality experiences suggests that the computation of these two variables might be distinct. One possibility is that this dissociation maps directly onto a distinction between first-order and second-order processes discussed above (Fig. 3). More concretely, this would mean that the quality of perceptual experiences is determined by first- 
1 order sensory processes while beliefs about reality are determined by higher-order monitoring mechanisms. Since these are two components of one reality monitoring system, both processes would generally be in line with each other, but because they rely on different neural substrates, they will sometimes dissociate.

In line with the idea that experience is determined by first-order processes, it has been suggested that differences in layer-specific activations in early visual cortex might directly account for whether something is experienced as real or imagined (Bergmann et al., 2019; Lawrence et al., 2018; Lawrence, Norris, \& De Lange, 2019). However, due to differences in target layers for feedforward and feedback signals, the layer profile of externally and internally triggered signals is very different (Fig. 1), making it unlikely that internally generated signals that are experienced as real (e.g. hallucinations) could evoke the same laminar activity profile as externally presented signals. Alternatively, the general strength and precision of sensory representations might determine the 'feel' of a sensory experience, with stronger and more precise signals feeling more real. In line with the idea that first-order representations determine experience, hallucinations with insight, such as in Charles Bonnet syndrome, have mostly been associated with spontaneous fluctuations in sensory activation (Hahamy, Wilf, Rosin, Behrmann, \& Malach, 2021), rather than dysfunctional frontal systems.

Furthermore, while research into the neural correlates of lucid dreaming is scarce, initial findings suggest that the involvement of anterior prefrontal cortex is found in lucid but not non-lucid dreams (Baird, Mota-Rolim, \& Dresler, 2019), despite both types of dreams having more real 'feel' than wakeful imagination. Interestingly, this dissociation between implicit and explicit monitoring has also been suggested to exist for metacognition (Carruthers, 2009; Nicholson, Williams, Lind, Grainger, \& Carruthers, 2020), with uncertainty or precision being encoded at various levels of the system (Meyniel et al., 2015; Pouget et al., 2016). For instance, information about confidence might already be represented within first-order visuomotor circuits without requiring the involvement of higher-order frontal areas (Kiani \& Shadlen, 2009). 
However, as discussed above, first-order mechanisms alone seem to be unable to account

2 for all source confusions. For example, the existence of very weak sensory signals that are still experienced as real as well as strong imagery that is still experienced as imagined suggests that sensory representations alone cannot account for the feeling of reality. Accordingly, it has been suggested that both conscious experience as well as knowledge about reality is determined by higher-order frontal monitoring systems (Lau, 2019). The difference between the two might then be how this system is employed: for instance, an automatic, implicit route might determine the feeling of reality while a more deliberate, explicit route determines beliefs about reality. These two processes might map unto separate neural systems within the frontal cortex. In terms of metacognitive processes, a relevant distinction can be made between regions of agranular posterior medial PFC (such as the perigenual anterior cingulate cortex; pgACC) and more anterior frontopolar cortex. The former has been shown to track "implicit" or automatic confidence evaluations in simple decisions (Bang \& Fleming, 2018; Morales et al., 2018; Wittmann et al., 2016), occurring very early in a trial (as revealed by simultaneous EEG-fMRI; (Gherman \& Philiastides, 2018). In contrast, frontopolar cortex has been found to track higher-order aspects of metacognitive evaluation, including the need to make explicit judgments (Bang et al., 2020; Gherman \& Philiastides, 2018; Fleming, Huijgen, \& Dolan, 2012), infer on the absence of stimulation (Mazor, Friston, \& Fleming, 2020; Miyamoto, Setsuie, Osada, \& Miyashita, 2018) and/or use metacognitive estimates for adjusting decision-making strategy (Donoso, Collins, \& Koechlin, 2014). Direct comparisons between the functional anatomy of metacognition and reality monitoring will be required to understand how these potentially distinct metacognitive processes contribute to different aspects of PRM.

Future research is also necessary to determine whether reality experience and belief are determined by mechanisms at different levels of the system (e.g. by first-order sensory versus second-order metacognitive processes respectively) or whether both are supported by a higherorder monitoring system employed in different ways. One concrete route to dissociating these two 
be imagined, such as hallucinations with insight or lucid dreaming, are also accompanied by changes within putative frontal reality monitoring systems and/or whether they reflect hyperactivation of first-order representations.

\section{Conclusion}

Deciding whether a sensory signal is real or imagined has important implications for behaviour as well as for perceptual processing in general. For example, the sensory representation of a bear will lead to a very different response when it is inferred to reflect reality (being scared and running away) compared to when it is merely imagined (being charmed and staying put). Furthermore, if the bear is real, our internal model of the world should be updated to accommodate the existence of bears in this specific environment, which is not necessary for imagined bears. A wealth of neuroimaging research has shown that imagined and perceived sensory experience employ similar neural mechanisms (Dijkstra et al., 2019; Pearson, 2019; Waters et al., 2021), potentially complicating this perceptual reality monitoring process. Despite its importance for general cognitive functioning, the neurocognitive mechanisms underlying perceptual reality monitoring remain largely unknown.

In this paper we first discussed the differences between internally and externally triggered sensory experiences which might be used to infer the source of sensory signals. We concluded that, in contrast to veridical perception, imagination is associated with weaker and less precise sensory representations, likely as a result of anatomical restrictions associated with running the visual system backwards (Breedlove et al., 2020; Dijkstra et al., 2020; Domingo, 2018). Accordingly, internally generated signals that are misattributed as real, e.g. hallucinations, are often associated with hyperactivation in sensory areas (Waters et al., 2021). Furthermore, imagination is associated with stronger cognitive control which renders it in some ways more predictable than veridical perception, resulting in a feeling of agency that dissociates it from externally triggered signals (Dijkstra et al., 2019; Haggard, 2017; Kosslyn et al., 2001). However, cognitive control of sensory 
1 signals is also employed during veridical perception; via top-down attention (Dijkstra et al., 2019;

2 Gazzaley \& Nobre, 2012). Furthermore, perception is more predictable than imagery in the sense

3 that it is both more constrained by our model of the external world and obeys sensorimotor contingencies, although recent evidence suggests this might also be true of imagery (Brincat et al., 2021; Gurtner et al., 2021). Together these observations suggest that while there are differences in sensory signals and cognitive control, there is no clear neural signature that unambiguously dissociates imagination from reality.

This ambiguity motivates the need for a perceptual reality monitoring mechanism that evaluates these different factors in order to form a decision about the likely source of sensory signals. Various lines of research suggest that the anterior medial prefrontal cortex (amPFC) might house such machinery (Powers et al., 2017; Simons et al., 2017). Perceptual reality monitoring might then be implemented within a multi-level system as a higher-order evaluation of the quality of sensory processing (Gershman, 2019). According to this view, reality monitoring is tightly linked to metacognition; the process of evaluating our own cognition (Lau, 2019). Within such a system, source confusion can arise from disruptions at different levels. One exciting avenue for future research is to investigate to what extent there is recurrence between different levels of the system such that source attributions are fed back to change sensory processing (e.g. Luhrmann et al., 2021; Rollwage et al., 2020). Furthermore, it remains unclear to what extent this high-level monitoring system is only important for explicit beliefs about reality or also determines whether something is experienced as real.

In conclusion, due to the overlap in neural machinery used for imagination and perception, determining whether a sensory experience reflects reality is a non-trivial process. Here, we suggest that perceptual reality monitoring might be implemented within a multi-level system in which higher-levels located in frontal areas monitor sensory signal strength and cognitive control to determine the source of a sensory experience. However, many open questions remain and future research is necessary to fully characterize the different elements of this mechanism. A better 


\section{6}

7

8

understanding of the mechanisms supporting perceptual reality monitoring will have important implications for our understanding of general cognitive function as well as clinical cases of source confusion.

\section{Acknowledgements}

N.D. is supported by a Rubicon grant from the Netherlands Organization for Scientific Research (NWO) [019.192SG.003], P.K. is supported by a Wellcome/Royal Society Sir Henry Dale Fellowship [218535/Z/19/Z], S.M.F. is supported by a Wellcome/Royal Society Sir Henry Dale Fellowship [206648/Z/17/Z] and a Philip Leverhulme Prize from the Leverhulme Trust. The Wellcome Centre for Human Neuroimaging is supported by core funding from the Wellcome Trust [206648/Z/17/Z]. For the purpose of Open Access, the author has applied a CC-BY copyright license to any author accepted manuscript version arising from this submission.

\section{Competing interests}

The authors declare that they have no competing interests.

\section{References}

Aitken, F., Turner, G., \& Kok, P. (2020). Prior expectations of motion direction modulate early sensory processing. The Journal of Neuroscience, 40(33), 6389-6397. https://doi.org/10.1523/JNEUROSCI.0537-20.2020

Aitken, F., Menelaou, G., Warrington, O., Koolschijn, R. S., Corbin, N., Callaghan, M. F., \& Kok, P. (2020). Prior expectations evoke stimulus-specific activity in the deep layers of the primary visual cortex. PLoS Biology, 18(12), e3001023. https://doi.org/10.1371/journal.pbio.3001023

Al-Tahan, H., \& Mohsenzadeh, Y. (2020). Reconstructing feedback representations in ventral visual pathway with a generative adversarial autoencoder. BioRxiv, 2020.07.23.218859. 
https://doi.org/10.1101/2020.07.23.218859

Albers, A. M., Kok, P., Toni, I., Dijkerman, H. C., \& De Lange, F. P. (2013). Shared representations for working memory and mental imagery in early visual cortex. Current Biology, 23, 1427-1431. https://doi.org/10.1016/j.cub.2013.05.065

Allen, P., Larøi, F., McGuire, P. K., \& Aleman, A. (2008). The hallucinating brain: A review of structural and functional neuroimaging studies of hallucinations. Neuroscience and Biobehavioral Reviews. https://doi.org/10.1016/j.neubiorev.2007.07.012

Badcock, J. C., \& Hugdahl, K. (2012). Examining the continuum model of auditory hallucinations: A review of cognitive mechanisms. Hallucinations: Research and Practice, (9781461409595), 317328. https://doi.org/10.1007/978-1-4614-0959-5_23

Badcock, J. C., Waters, F. A. V., Maybery, M. T., \& Michie, P. T. (2005). Auditory hallucinations: Failure to inhibit irrelevant memories. Cognitive Neuropsychiatry. 10(2), 125-36. https://doi.org/10.1080/13546800344000363

Badre, D., \& Nee, D. E. (2018). Frontal Cortex and the Hierarchical Control of Behavior. Trends in Cognitive Sciences, 22(2), 170-188. https://doi.org/10.1016/j.tics.2017.11.005

Baird, B., Mota-Rolim, S. A., \& Dresler, M. (2019, May 1). The cognitive neuroscience of lucid dreaming. Neuroscience and Biobehavioral Reviews, 100, 305-323. https://doi.org/10.1016/j.neubiorev.2019.03.008

Balsdon, T., Wyart, V., \& Mamassian, P. (2020). Confidence controls perceptual evidence accumulation. Nature Communications, 11(1), 1-11. https://doi.org/10.1038/s41467-02015561-w

Bang, D., Ershadmanesh, S., Nili, H., \& Fleming, S. M. (2020). Private-public mappings in human prefrontal cortex. ELife, 9, 1-25. https://doi.org/10.7554/eLife.56477

Bang, D., \& Fleming, S. M. (2018). Distinct encoding of decision confidence in human medial prefrontal cortex. Proceedings of the National Academy of Sciences of the United States of America, 115(23), 6082-6087. https://doi.org/10.1073/pnas.1800795115 
Barron, H. C., Auksztulewicz, R., \& Friston, K. (2020). Prediction and memory: a predictive coding account. Progress in Neurobiology, 101821. https://doi.org/10.1016/j.pneurobio.2020.101821

Barron, H. C., Dolan, R. J., \& Behrens, T. E. J. (2013). Online evaluation of novel choices by simultaneous representation of multiple memories. Nature Neuroscience, 16(10), 1492-1498. https://doi.org/10.1038/nn.3515

Bastos, A. M., Usrey, W. M., Adams, R. A., Mangun, G. R., Fries, P., \& Friston, K. J. (2012). Canonical Microcircuits for Predictive Coding. Neuron, 76, 695-711. https://doi.org/10.1016/j.neuron.2012.10.038

Bergmann, J., Morgan, A. T., \& Muckli, L. (2019). Two distinct feedback codes in V1 for 'real' and 'imaginary' internal experiences. BioRxiv, 664870. https://doi.org/10.1101/664870

Breedlove, J. L., St-Yves, G., Olman, C. A., \& Naselaris, T. (2020). Generative Feedback Explains Distinct Brain Activity Codes for Seen and Mental Images. Current Biology, 30, 1-4. https://doi.org/10.1016/j.cub.2020.04.014

Brincat, S. L., Donoghue, J. A., Mahnke, M. K., Kornblith, S., Lundqvist, M., \& Miller, E. K. (2021). Interhemispheric transfer of working memories. Neuron, 109, 1055-1066. https://doi.org/10.1016/j.neuron.2021.01.016

Buda, M., Fornito, A., Bergström, Z. M., \& Simons, J. S. (2011). A specific brain structural basis for individual differences in reality monitoring. Journal of Neuroscience, 31(40), 14308-14313. https://doi.org/10.1523/JNEUROSCI.3595-11.2011

Carruthers, P. (2009). How we know our own minds: The relationship between mindreading and metacognition. Behavioral and Brain Sciences, 32, $121-138$. https://doi.org/10.1017/S0140525X09000545

Christophel, T. B., Hebart, M. N., \& Haynes, J.-D. (2012). Decoding the Contents of Visual Short-Term Memory from Human Visual and Parietal Cortex. Journal of Neuroscience, 32(38), 1298312989. https://doi.org/10.1523/JNEUROSCI.0184-12.2012

Christophel, Thomas B., Klink, P. C., Spitzer, B., Roelfsema, P. R., \& Haynes, J.-D. (2017). The 
Distributed Nature of Working Memory. Trends in Cognitive Sciences, 21(2), 111-124. https://doi.org/10.1016/j.tics.2016.12.007

Corlett, P. R., Canavan, S. V., Nahum, L., Appah, F., \& Morgan, P. T. (2014). Dreams, reality and memory: Confabulations in lucid dreamers implicate reality-monitoring dysfunction in dream $\begin{array}{lll}\text { consciousness. } \quad \text { Cognitive } \quad \text { Neuropsychiatry, } & \text { 19(6), }\end{array}$ https://doi.org/10.1080/13546805.2014.932685

Corlett, Philip R, Horga, G., Fletcher, P. C., Alderson-Day, B., Schmack, K., \& Powers, A. R. (2019). Hallucinations and Strong Priors. Trends in Cognitive Sciences, 23, 114-127. https://doi.org/10.1016/j.tics.2018.12.001

Crick, F., \& Koch, C. (1998). Constraints on cortical and thalamic projections: The no-strong-loops hypothesis. Nature, 391, 245-250. https://doi.org/10.1038/34584

Cui, X., Jeter, C. B., Yang, D., Montague, P. R., \& Eagleman, D. M. (2007). Vividness of mental imagery: Individual variability can be measured objectively. Vision Research, 47, 474-478. https://doi.org/10.1016/j.visres.2006.11.013

David, A. S. (2004). The cognitive neuropsychiatry of auditory verbal hallucinations: An overview. Cognitive Neuropsychiatry, 9, 107-23. https://doi.org/10.1080/13546800344000183

Davies, G., \& Greenwood, K. (2020, September 2). A meta-analytic review of the relationship between neurocognition, metacognition and functional outcome in schizophrenia. Journal of Mental Health, 29, 496-505. https://doi.org/10.1080/09638237.2018.1521930

de Lange, F. P., Heilbron, M., \& Kok, P. (2018). How Do Expectations Shape Perception? Trends in Cognitive Sciences, 22(9), 764-779. https://doi.org/10.1016/j.tics.2018.06.002

Dentico, D., Cheung, B. L., Chang, J.-Y., Guokas, J., Boly, M., Tononi, G., \& Van Veen, B. (2014). Reversal of cortical information flow during visual imagery as compared to visual perception. Neurolmage, 100, 237-243. https://doi.org/10.1016/j.neuroimage.2014.05.081

Dijkstra, N., Bosch, S. E., \& van Gerven, M. A. J. (2017). Vividness of visual imagery depends on the neural overlap with perception in visual areas. Journal of Neuroscience, 37(5). 
https://doi.org/10.1523/JNEUROSCI.3022-16.2016

Dijkstra, N., Zeidman, P., Ondobaka, S., Van Gerven, M. A. J., \& Friston, K. (2017). Distinct Top-down and Bottom-up Brain Connectivity during Visual Perception and Imagery. Scientific Reports, 7(1). https://doi.org/10.1038/s41598-017-05888-8

Dijkstra, N., Ambrogioni, L., Vidaurre, D., \& van Gerven, M. (2020). Neural dynamics of perceptual inference and its reversal during imagery. ELife, 9, 1-19. https://doi.org/10.7554/eLife.53588

Dijkstra, N., Bosch, S. E., \& van Gerven, M. A. J. (2019). Shared Neural Mechanisms of Visual Perception and Imagery. Trends in Cognitive Sciences, 23(5), 423-434 https://doi.org/10.1016/j.tics.2019.02.004

Dijkstra, N., Mostert, P., de Lange, F. P., Bosch, S., \& van Gerven, M. A. J. (2018). Differential temporal dynamics during visual imagery and perception. ELife, 7, 1-16. https://doi.org/10.1101/226217

Dijkstra, N., Mazor, M., Kok, P., \& Fleming, S. (2021). Mistaking imagination for reality: Congruent mental imagery leads to more liberal perceptual detection. Cognition, 212, 104719. https://doi.org/10.1016/j.cognition.2021.104719

Domingo, J. L., Treder, M.S., Kerrén, C., \& Wimber, M. (2018). Evidence for a reversal of the neural information flow between object perception and object reconstruction from memory. Nature Communications, 179, 1-28. https://doi.org/10.1101/300913

Donoso, M., Collins, A. G. E., \& Koechlin, E. (2014). Foundations of human reasoning in the prefrontal cortex. Science, 344(6191), 1481-1486. https://doi.org/10.1126/science.1252254

Drori, G., Bar-Tal, P., Stern, Y., Zvilichovsky, Y., \& Salomon, R. (2020). UnReal? Investigating the Sense of Reality and Psychotic Symptoms with Virtual Reality. Journal of Clinical Medicine, 9(6), 1627. https://doi.org/10.3390/jcm9061627

El Haj, M., Badcock, J. C., Jardri, R., Larøi, F., Roche, J., Sommer, I. E., \& Gallouj, K. (2019). A look into hallucinations: the relationship between visual imagery and hallucinations in Alzheimer's disease. 
https://doi.org/10.1080/13546805.2019.1632180

Epstein, R. A. (2008, October 1). Parahippocampal and retrosplenial contributions to human spatial navigation. Trends in Cognitive Sciences, 12, 388-396. https://doi.org/10.1016/j.tics.2008.07.004

Faivre, N., Roger, M., Pereira, M., de Gardelle, V., Vergnaud, J. C., Passerieux, C., \& Roux, P. (2019, December 18). Confidence in perceptual decision-making is preserved in schizophrenia. MedRxiv, p. 2019.12.15.19014969. https://doi.org/10.1101/2019.12.15.19014969

Favila, S., Kuhl, B., \& Winawer, J. (2020). Spatial perception and memory have distinct activation profiles in human visual cortex. BioRxiv, 811331. https://doi.org/10.1101/811331

Fazekas, P. (2021). Hallucinations as intensified forms of mind-wandering. Philosophical Transactions of the Royal Society B: Biological Sciences, 376(1817), 20190700. https://doi.org/10.1098/rstb.2019.0700

Fazekas, P., Nemeth, G., \& Overgaard, M. (2020). Perceptual Representations and the Vividness of Stimulus-Triggered and Stimulus-Independent Experiences. Perspectives on Psychological Science, 15(5). https://doi.org/10.1177/1745691620924039

Felleman, D. J., \& Van Essen, D. C. (1991). Distributed hierarchical processing in the primate cerebral cortex. Cerebral Cortex, 1(1), 1-47. https://doi.org/10.1093/cercor/1.1.1

Finke, R. A. (1986). Some consequences of visualization in pattern identification and detection. The American Journal of Psychology, 99(2), 257-274. https://doi.org/10.2307/1422278

Fleming, S. M., \& Lau, H. C. (2014, July 15). How to measure metacognition. Frontiers in Human Neuroscience, 8, 1-9. https://doi.org/10.3389/fnhum.2014.00443

Fleming, S. M., Van Der Putten, E. J., \& Daw, N. D. (2018). Neural mediators of changes of mind about perceptual decisions. Nature Neuroscience, 21(4), 617-624. https://doi.org/10.1038/s41593-018-0104-6

Fleming, P. R., Dolan, R. J., \& Fleming, S. M. (2012). The neural basis of metacognitive ability Subject collections The neural basis of metacognitive ability. Philosophical Transactions of the Royal 

Society B: Biological Sciences, 367(2012), 1338-1349. https://doi.org/10.1098/rstb.2011.0417

Fletcher, P. C., \& Frith, C. D. (2009). Perceiving is believing: a Bayesian approach to explaining the positive symptoms of schizophrenia. Nature Reviews Neuroscience, 10(1), 48-58. https://doi.org/10.1038/nrn2536

Foote, B., Smolin, Y., Kaplan, M., Legatt, M. E., \& Lipschitz, D. (2006). Prevalence of dissociative disorders in psychiatric outpatients. American Journal of Psychiatry, 163(4), 623-629. https://doi.org/10.1176/ajp.2006.163.4.623

Fornito, A., Yücel, M., Wood, S. J., Proffitt, T., McGorry, P. D., Velakoulis, D., \& Pantelis, C. (2006). Morphology of the paracingulate sulcus and executive cognition in schizophrenia. Schizophrenia Research, 88, 192-7. https://doi.org/10.1016/j.schres.2006.06.034

Fracasso, A., Petridou, N., \& Dumoulin, S. O. (2016). Systematic variation of population receptive field properties across cortical depth in human visual cortex. Neurolmage, 139, 427-438. https://doi.org/10.1016/j.neuroimage.2016.06.048

Friston, K. (2005). A theory of cortical responses. Philosophical Transactions of the Royal Society of London B: Biological Sciences, 360(1456).

Frith, C. D., Blakemore, S. J., \& Wolpert, D. M. (2000). Abnormalities in the awareness and control of action. Philosophical Transactions of the Royal Society B: Biological Sciences, 355(104), 17711788. https://doi.org/10.1098/rstb.2000.0734

Fu, Q., Liu, Y. J., Dienes, Z., Wu, J., Chen, W., \& Fu, X. (2017). Neural correlates of subjective awareness for natural scene categorization of color photographs and line-drawings. Frontiers in Psychology. https://doi.org/10.3389/fpsyg.2017.00210

Ganis, G., Thompson, W. L., \& Kosslyn, S. M. (2004). Brain areas underlying visual mental imagery and visual perception: an fMRI study. Cognitive Brain Research, 20(2), 226-241. https://doi.org/10.1016/j.cogbrainres.2004.02.012

Garrison, J. R., Fernyhough, C., McCarthy-Jones, S., Haggard, M., Carr, V., Schall, U., ... Simons, J. S. (2015). Paracingulate sulcus morphology is associated with hallucinations in the human brain. 

Nature Communications. https://doi.org/10.1038/ncomms9956

Garrison, J. R., Fernyhough, C., McCarthy-Jones, S., Simons, J. S., \& Sommer, I. E. C. (2019). Paracingulate sulcus morphology and hallucinations in clinical and nonclinical groups. Schizophrenia Bulletin, 45(4), 733-741. https://doi.org/10.1093/schbul/sby157

Gattass, R., Nascimento-Silva, S., Soares, J. G. M., Lima, B., Jansen, A. K., Diogo, A. C. M., ... Fiorani, M. (2005). Cortical visual areas in monkeys: Location, topography, connections, columns, plasticity and cortical dynamics. Philosophical Transactions of the Royal Society B: Biological Sciences, 360, 709-31. https://doi.org/10.1098/rstb.2005.1629

Gazzaley, A., \& Nobre, A. C. (2012). Top-down modulation: Bridging selective attention and working memory. Trends in Cognitive Sciences, 16, 129-135. https://doi.org/10.1016/j.tics.2011.11.014

Gershman, S. J. (2019). The Generative Adversarial Brain. Frontiers in Artificial Intelligence, 2, 18. https://doi.org/10.3389/frai.2019.00018

Gherman, S., \& Philiastides, M. G. (2018). Human VMPFC encodes early signatures of confidence in perceptual decisions. ELife, 7. https://doi.org/10.7554/eLife.38293

Griffin, J. D., \& Fletcher, P. C. (2017). Predictive Processing, Source Monitoring, and Psychosis. Annual Review of Clinical Psychology, 13(1), 265-289. https://doi.org/10.1146/annurev-clinpsy032816-045145

Gurtner, L. M., Hartmann, M., \& Mast, F. W. (2021). Eye movements during visual imagery and perception show spatial correspondence but have unique temporal signatures. Cognition, 210, 104597. https://doi.org/10.1016/j.cognition.2021.104597

Haarsma, J., Fletcher, P. C., Griffin, J. D., Taverne, H. J., Ziauddeen, H., Spencer, T. J., ... Murray, G. K. (2020). Precision weighting of cortical unsigned prediction error signals benefits learning, is mediated by dopamine, and is impaired in psychosis. Molecular Psychiatry, 1-14. https://doi.org/10.1038/s41380-020-0803-8

Haggard, P. (2017). Sense of agency in the human brain. Nature Reviews Neuroscience, 18, 196-207. https://doi.org/10.1038/nrn.2017.14 
Hahamy, A., Wilf, M., Rosin, B., Behrmann, M., \& Malach, R. (2021). How do the blind 'see'? The role of spontaneous brain activity in self-generated perception. Brain, 144(1), 340-353. https://doi.org/10.1093/brain/awaa384

Harrison, S. A., \& Tong, F. (2009). Decoding reveals the contents of visual working memory in early visual areas. Nature, 458(7238), 632-635. https://doi.org/10.1038/nature07832

Hochstein, S., \& Ahissar, M. (2002). View from the Top: Hierarchies and Reverse Hierarchies in the Visual System. Neuron, 36(5), 791-804. https://doi.org/10.1016/S0896-6273(02)01091-7

Honig, A., Romme, M. A., Ensink, B. J., Escher, S. D., Pennings, M. H., \& deVries, M. W. (1998). Auditory hallucinations: a comparison between patients and nonpatients. The Journal of Nervous and Mental Disease, 186(10), 646-651. Retrieved from http://www.ncbi.nlm.nih.gov/pubmed/9788642

Horikawa, T., Tamaki, M., Miyawaki, Y., \& Kamitani, Y. (2013). Neural decoding of visual imagery during sleep. Science, 340(6132), 639-642. https://doi.org/10.1126/science.1234330

Hupé, J. M., James, A. C., Payne, B. R., Lomber, S. G., Girard, P., \& Bullier, J. (1998). Cortical feedback improves discrimination between figure and background by V1, V2 and V3 neurons. Nature, 394(6695), 784-787. https://doi.org/10.1038/29537

Ishai, A., Ungerleider, L. G., \& Haxby, J. V. (2000). Distributed Neural Systems for the Generation of Visual Images. Neuron, 28, 979-990. https://doi.org/10.1016/S0896-6273(00)00168-9

Jardri, R., \& Denève, S. (2013). Circular inferences in schizophrenia. Brain, 136(11), 3227-3241. https://doi.org/10.1093/brain/awt257

Johnson, M., Hashtroudi, S., \& Lindsay, S. (1993). Source monitoring. Psychological Bulletin, 114, 328. https://doi.org/10.1037/0033-2909.114.1.3

Johnson, M. K., \& Raye, C. L. (1981a). Reality monitoring. Psychological Review, 88(1), 67-85. https://doi.org/10.1037/0033-295X.88.1.67

Johnson, M. K., \& Raye, C. L. (1981b). Reality monitoring. Psychological Review, 88(1), 67-85. https://doi.org/10.1037/0033-295X.88.1.67 
Johnson, M. K., Raye, C. L., Foley, H. J., \& Foley, M. A. (1981). Cognitive Operations and Decision Bias in Reality Monitoring. The American Journal of Psychology, 94(1), 37. https://doi.org/10.2307/1422342

Kensinger, E. A., \& Schacter, D. L. (2006). Neural processes underlying memory attribution on a reality-monitoring task. Cerebral Cortex. https://doi.org/10.1093/cercor/bhj054

Kersten, D., Mamassian, P., \& Yuille, A. (2004). Object perception as Bayesian inference. Annu. Rev. Psychol, 55, 271-304. https://doi.org/10.1146/annurev.psych.55.090902.142005

Kiani, R., \& Shadlen, M. N. (2009). Representation of confidence associated with a decision by neurons in the parietal cortex. Science, 324(5928), 759-764. https://doi.org/10.1126/science.1169405

Klink, P. C., Dagnino, B., Gariel-Mathis, M. A., \& Roelfsema, P. R. (2017). Distinct Feedforward and Feedback Effects of Microstimulation in Visual Cortex Reveal Neural Mechanisms of Texture Segregation. Neuron, 95, 209-220. https://doi.org/10.1016/j.neuron.2017.05.033

Koenig-Robert, R., \& Pearson, J. (2021). Why do imagery and perception look and feel so different? Philosophical Transactions of the Royal Society B: Biological Sciences, 376(1817), 20190703. https://doi.org/10.1098/rstb.2019.0703

Kok, P., Bains, L. J., Van Mourik, T., Norris, D. G., \& De Lange, F. P. (2016). Selective activation of the deep layers of the human primary visual cortex by top-down feedback. Current Biology, 26(3), 371-376. https://doi.org/10.1016/j.cub.2015.12.038

Konkoly, K., Appel, K., Chabani, E., Mironov, A. Y., Mangiaruga, A., Gott, J., ... Paller, K. (2021). RealTime Dialogue between Experimenters and Dreamers During rem Sleep. Current Biology, 31, 111. https://doi.org/10.2139/ssrn.3606772

Kosslyn, S. M., Ganis, G., \& Thompson, W. L. (2001). Neural Foundations of Imagery. Nature Reviews Neuroscience, 2(9), 635-642. https://doi.org/10.1038/35090055

Larkum, M. (2013). A cellular mechanism for cortical associations: An organizing principle for the cerebral cortex. Trends in Neurosciences, 36, 141-151. 
https://doi.org/10.1016/j.tins.2012.11.006

Lau, H. (2019). Consciousness, Metacognition, \& Perceptual Reality Monitoring. PsyArXiv. https://doi.org/10.31234/osf.io/ckbyf

Lawrence, S. J. D., van Mourik, T., Kok, P., Koopmans, P. J., Norris, D. G., \& de Lange, F. P. (2018). Laminar Organization of Working Memory Signals in Human Visual Cortex. Current Biology, 28(21), 3435-3440. https://doi.org/10.1016/j.cub.2018.08.043

Lawrence, S. J., Norris, D. G., \& De Lange, F. P. (2019). Dissociable laminar profiles of concurrent bottom-up and top-down modulation in the human visual cortex. ELife, 8, 498873. https://doi.org/10.7554/eLife.44422

Lawrie, S. M., Buechel, C., Whalley, H. C., Frith, C. D., Friston, K. J., \& Johnstone, E. C. (2002). Reduced frontotemporal functional connectivity in schizophrenia associated with auditory hallucinations. Biological Psychiatry, 51(12), 1008-11. https://doi.org/10.1016/S0006$3223(02) 01316-1$

Lee, S.-H., Kravitz, D. J., \& Baker, C. I. (2012). Disentangling visual imagery and perception of real$\begin{array}{llll}\text { world } & \text { objects. } & \text { Neurolmage, } & \text { 59(4), }\end{array}$ https://doi.org/10.1016/j.neuroimage.2011.10.055

Lee, T. S., \& Mumford, D. (2003). Hierarchical Bayesian inference in the visual cortex. Journal of the Optical Society of America, 20, 1434. https://doi.org/10.1364/josaa.20.001434

Lin, X., Zhuo, C., Li, G., Li, J., Gao, X., Chen, C., \& Jiang, D. (2020). Functional brain alterations in auditory hallucination subtypes in individuals with auditory hallucinations without the diagnosis of specific neurological diseases and mental disorders at the current stage. Brain and Behavior. https://doi.org/10.1002/brb3.1487

Linde-Domingo, J., Treder, M. S., Kerren, C., \& Wimber, M. (2019). Evidence for a reversal of the neural information flow between object perception and object reconstruction from memory. Nature Communications, 10(1), 300913. https://doi.org/10.1001/archderm.143.9.1131

Luhrmann, T. M., Weisman, K., Aulino, F., Brahinsky, J. D., Dulin, J. C., Dzokoto, V. A., ... Smith, R. E. 
(2021). Sensing the presence of gods and spirits across cultures and faiths. Proceedings of the National Academy of Sciences, 118(5), e2016649118. https://doi.org/10.1073/pnas.2016649118

Markham, R., \& Hynes, L. (1993). The effect of vividness of imagery on reality monitoring. Journal of Mental Imagery, 17(3-4), 159-170. Retrieved from https://psycnet.apa.org/record/1994$12397-001$

Martarelli, C. S., \& Mast, F. W. (2021). Pictorial low-level features in mental images: evidence from eye fixations. Psychological Research, 1, 3. https://doi.org/10.1007/s00426-021-01497-3

Mast, F. W., \& Kosslyn, S. M. (2002, July 1). Eye movements during visual mental imagery. Trends in Cognitive Sciences, 6, 271-272. https://doi.org/10.1016/S1364-6613(02)01931-9

Mazor, M., Friston, K., \& Fleming, S. (2020). Distinct neural contributions to metacognition for detecting, but not discriminating visual stimuli. ELife, 9, 1-34. https://doi.org/10.1101/853366

McCarthy-Jones, S., \& Longden, E. (2016). Auditory verbal hallucinations in schizophrenia and posttraumatic stress disorder: Common phenomenology, common cause, common interventions? Frontiers in Psychology, 6(1). https://doi.org/10.3389/fpsyg.2015.01071

Mechelli, A., Allen, P., Amaro, E., Fu, C. H. Y., Williams, S. C. R., Brammer, M. J., ... McGuire, P. K. (2007). Misattribution of speech and impaired connectivity in patients with auditory verbal hallucinations. Human Brain Mapping, 28, 1213-22. https://doi.org/10.1002/hbm.20341

Mechelli, A., Price, C. J., Friston, K. J., \& Ishai, A. (2004). Where bottom-up meets top-down: neuronal interactions during perception and imagery. Cerebral Cortex, 14(11), 1256-1265. https://doi.org/10.1093/cercor/bhh087

Mendoza-Halliday, D., \& Martinez-Truijilo, J.C. (2017). Neuronal population coding of perceived and memorized visual features in lateral prefrontal cortex. Nature Communications, 15471.

Miller, E. K. (2000). The prefontral cortex and cognitive control. Nature Reviews Neuroscience, 1, 5965. https://doi.org/10.1038/35036228

Miller, E. K., \& Cohen, J. D. (2001). An Integrative Theory of Prefrontal Cortex Function. Annual 
Review of Neuroscience, 24(1), 167-202. https://doi.org/10.1146/annurev.neuro.24.1.167

Miyamoto, K., Setsuie, R., Osada, T., \& Miyashita, Y. (2018). Reversible Silencing of the Frontopolar Cortex Selectively Impairs Metacognitive Judgment on Non-experience in Primates. Neuron, 97(4), 980-989.e6. https://doi.org/10.1016/j.neuron.2017.12.040

Morales, J., Lau, H., \& Fleming, S. M. (2018). Domain-general and domain-specific patterns of activity supporting metacognition in human prefrontal cortex. Journal of Neuroscience, 38(14), 35343546. https://doi.org/10.1523/JNEUROSCI.2360-17.2018

Moritz, S., Woodward, T. S., Jelinek, L., \& Klinge, R. (2008). Memory and metamemory in schizophrenia: A liberal acceptance account of psychosis. Psychological Medicine, 38(6), 825832. https://doi.org/10.1017/S0033291707002553

Moritz, Steffen, Woodward, T. S., \& Rodriguez-Raecke, R. (2006). Patients with schizophrenia do not produce more false memories than controls but are more confident in them. Psychological Medicine, 36(5), 659-667. https://doi.org/10.1017/S0033291706007252

Motes, M. A., Malach, R., \& Kozhevnikov, M. (2008). Object-processing neural efficiency differentiates object from spatial visualizers. NeuroReport, 19, 1727-31. https://doi.org/10.1097/WNR.0b013e328317f3e2

Mugan, U., \& Maclver, M. A. (2020). Spatial planning with long visual range benefits escape from visual predators in complex naturalistic environments. Nature Communications, 11(1), 1-14. https://doi.org/10.1038/s41467-020-16102-1

Naselaris, T., Olman, C. A., Stansbury, D. E., Ugurbil, K., \& Gallant, J. L. (2015a). A voxel-wise encoding model for early visual areas decodes mental images of remembered scenes. Neurolmage, 105, 215-228. https://doi.org/10.1016/j.neuroimage.2014.10.018

Naselaris, T., Olman, C. A., Stansbury, D. E., Ugurbil, K., \& Gallant, J. L. (2015b). A voxel-wise encoding model for early visual areas decodes mental images of remembered scenes. Neurolmage, 105, 215-228. https://doi.org/10.1016/j.neuroimage.2014.10.018

Nicholson, T., Williams, D. M., Lind, S. E., Grainger, C., \& Carruthers, P. (2020). Linking Metacognition 
and Mindreading: Evidence From Autism and Dual-Task Investigations. Journal of Experimental Psychology: General, 150(2), 206-220. https://doi.org/10.1037/xge0000878

New, J., \& Scholl, B. (2008). "Perceptual scotoma's" A functional account of motion induced blindess. Psychological Science, 19(7), 653.

New, J., \& Scholl, B. (2018). Motion-induced blindness for dynamic targets: further explorations of the perceptual scotoma hypothesis. Journal of Vision, 18(9), 1-13.

Okada, H., \& Matsuoka, K. (1992). Effects of auditory imagery on the detection of a pure tone in white noise: experimental evidence of the auditory Perky effect. Perceptual and Motor Skills, 74(2), 443-448. https://doi.org/10.2466/pms.1992.74.2.443

Pearson, J. (2014). New Directions in Mental-Imagery Research: The Binocular-Rivalry Technique and Decoding fMRI Patterns. Current Directions in Psychological Science, 23, 178-183. https://doi.org/10.1177/0963721414532287

Pearson, Joel. (2019). The human imagination: the cognitive neuroscience of visual mental imagery. Nature Reviews Neuroscience, 20, 624-634. https://doi.org/10.1038/s41583-019-0202-9

Pearson, Joel, \& Kosslyn, S. M. (2015). The heterogeneity of mental representation: Ending the imagery debate. Proceedings of the National Academy of Sciences of the United States of America, 112(33), 10089-10092. https://doi.org/10.1073/pnas.1504933112

Pearson, Joel, Naselaris, T., Holmes, E. A., \& Kosslyn, S. M. (2015). Mental Imagery: Functional Mechanisms and Clinical Applications. Trends in Cognitive Sciences, 19(10), 590-602. https://doi.org/10.1016/j.tics.2015.08.003

Perky, C. W. (1910). An Experimental Study of Imagination. The American Journal of Psychology, 21(3), 422. https://doi.org/10.2307/1413350

Powers, A. R., Mathys, C., \& Corlett, P. R. (2017). Pavlovian conditioning-induced hallucinations result from overweighting of perceptual priors. Science, 357(6351), 596-600. https://doi.org/10.1126/science.aan3458

Powers, A. R., III, Kelley, M., \& Corlett, P. R. (2016). Hallucinations as top-down effects on 
perception. Biological psychiatry. Cognitive neuroscience and neuroimaging, 1(5), 393-400. https://doi.org/10.1016/j.bpsc.2016.04.003

Press, C., Kok, P., \& Yon, D. (2020). The Perceptual Prediction Paradox. Trends in Cognitive Sciences, 24, 13-24. https://doi.org/10.1016/j.tics.2019.11.003

Reddy, L., Tsuchiya, N., \& Serre, T. (2010). Reading the mind's eye: decoding category information $\begin{array}{llll}\text { during } & \text { mental } & \text { imagery. } & \text { Neurolmage, }\end{array}$ https://doi.org/10.1016/j.neuroimage.2009.11.084

Redish, A. D. (2016). Vicarious trial and error. Nature Reviews Neuroscience, 17, 147-159. https://doi.org/10.1038/nrn.2015.30

Reeves, A. (1981). Visual imagery lowers sensitivity to hue-varying, but not to luminance-varying, visual stimuli. Perception \& Psychophysics, 29(3), 247-250. https://doi.org/10.3758/BF03207291

Ress, D., \& Heeger, D. J. (2003). Neuronal correlates of perception in early visual cortex. Nature Neuroscience, 6(4), 414-420. https://doi.org/10.1038/nn1024

Ridderinkhof, K. R., Ullsperger, M., Crone, E. A., \& Nieuwenhuis, S. (2004). The role of the medial frontal cortex in cognitive control. Science, 306, 443-447. https://doi.org/10.1126/science.1100301

Rivera-Aparicio, J., Yu, Q., \& Firestone, C. (2021). Hi-def memories of lo-def scenes. Psychonomic Bulletin and Review, 1-9. https://doi.org/10.3758/s13423-020-01829-1

Robin, F. (2010). Imagery and memory illusions. Phenomenology and the Cognitive Sciences, 9, 253262. https://doi.org/10.1177/0276236615574488

Robin, F, \& Mahé, A. (2015). Effects of image and verbal generation on false memory. Imagination, Cogntion and Personality, 35, 26-46.

Rollwage, M., Loosen, A., Hauser, T. U., Moran, R., Dolan, R. J., \& Fleming, S. M. (2020). Confidence drives a neural confirmation bias. Nature Communications, 11(1), 1-11. https://doi.org/10.1038/s41467-020-16278-6 
Sack, A. T., Van De Ven, V. G., Etschenberg, S., Schatz, D., \& Linden, D. E. J. (2005). Enhanced vividness of mental imagery as a trait marker of schizophrenia? Schizophrenia Bulletin, 31, 97104. https://doi.org/10.1093/schbul/sbi011

Schacter, D. L., Addis, D. R., Hassabis, D., Martin, V. C., Spreng, R. N., \& Szpunar, K. K. (2012, November 21). The Future of Memory: Remembering, Imagining, and the Brain. Neuron, 76, 677-694. https://doi.org/10.1016/j.neuron.2012.11.001

Seal, M. L., Crowe, S. F., \& Cheung, P. (1997). Deficits in source monitoring in subjects with auditory hallucinations may be due to differences in verbal intelligence and verbal memory. Cognitive Neuropsychiatry, 2(4), 273-290. https://doi.org/10.1080/135468097396289

Segal, S. J., \& Fusella, V. (1970). Influence of imaged pictures and sounds on detection of visual and auditory signals. Journal of Experimental Psychology, 83(3), 458-464. https://doi.org/10.1037/h0028840

Segal, S. J., \& Glicksman, M. (1967). Relaxation and the Perky effect: the influence of body position on judgments of imagery. The American Journal of Psychology, 80(2), 257-262. https://doi.org/10.2307/1420985

Segal, S. J., \& Gordon, P. E. (1969). The Perky effect revisited: Blocking of visual signals by imagery. Perceptual and Motor Skills, 28(3), 791-797. https://doi.org/10.2466/pms.1969.28.3.791

Segal, S. J., \& Nathan, S. (1964). The Perky Effect: Incorporation of an External Stimulus into an Imagery Experience under Placebo and Control Conditions. Perceptual and Motor Skills, 18(2), 385-395. https://doi.org/10.2466/pms.1964.18.2.385

Seth, A. K. (2014). A predictive processing theory of sensorimotor contingencies: Explaining the puzzle of perceptual presence and its absence in synesthesia. Cognitive Neuroscience, 5, 97118. https://doi.org/10.1080/17588928.2013.877880

Shine, J. M., Keogh, R., O’Callaghan, C., Muller, A. J., Lewis, S. J. G., \& Pearson, J. (2015). Imagine that: Elevated sensory strength of mental imagery in individuals with Parkinson's disease and visual hallucinations. Proceedings of the Royal Society B: Biological Sciences, 282, 2014-2047. 
https://doi.org/10.1098/rspb.2014.2047

Siclari, F., Baird, B., Perogamvros, L., Bernardi, G., LaRocque, J. J., Riedner, B., ... Tononi, G. (2017). The neural correlates of dreaming. Nature Neuroscience, 20(6), 872-878. https://doi.org/10.1038/nn.4545

Simons, J. S., Davis, S. W., Gilbert, S. J., Frith, C. D., \& Burgess, P. W. (2006). Discriminating imagined from perceived information engages brain areas implicated in schizophrenia. Neurolmage, 32, 696-703. https://doi.org/10.1016/j.neuroimage.2006.04.209

Simons, J. S., Garrison, J. R., \& Johnson, M. K. (2017). Brain Mechanisms of Reality Monitoring. Trends in Cognitive Sciences, 21(6), 462-473. https://doi.org/10.1016/j.tics.2017.03.012

Slade, P. D. (1976). An investigation of psychological factors involved in the predisposition to $\begin{array}{llll}\text { auditory hallucinations. } & \text { Psychological }\end{array}$ https://doi.org/10.1017/S0033291700007558

Sommer, I. E., Daalman, K., Rietkerk, T., Diederen, K. M., Bakker, S., Wijkstra, J., \& Boks, M. P. M. (2010). Healthy individuals with auditory verbal hallucinations; Who are they? psychiatric assessments of a selected sample of 103 subjects. Schizophrenia Bulletin, 63, 633-41. https://doi.org/10.1093/schbul/sbn130

Stebbins, G. T., Goetz, G. G., Carrillo, M. C., Bangen, K. J., Turner, D. A., Glover, G. H., \& Gabrieli, J. D. E. (2004). Altered cortical visual processing in PD with hallucinations: An fMRI study. Neurology, 63, 1409-16. https://doi.org/10.1212/01.WNL.0000141853.27081.BD

Stephan-Otto, C., Siddi, S., Senior, C., Cuevas-Esteban, J., Cambra-Martí, M. R., Ochoa, S., \& Brébion, G. (2017). Remembering verbally-presented items as pictures: Brain activity underlying visual mental images in schizophrenia patients with visual hallucinations. Cortex, 94, 113-122. https://doi.org/10.1016/j.cortex.2017.06.009

Sterzer, P., Adams, R. A., Fletcher, P., Frith, C., Lawrie, S. M., Muckli, L., ... Corlett, P. R. (2018). The Predictive Coding Account of Psychosis. Biological Psychiatry, 84, 634-643. https://doi.org/10.1016/j.biopsych.2018.05.015 
1 Tagliabue, C. F., Mazzi, C., Bagattini, C., \& Savazzi, S. (2016). Early local activity in temporal areas

2 reflects graded content of visual perception. Frontiers in Psychology. https://doi.org/10.3389/fpsyg.2016.00572

Tien, A. Y. (1991). Distribution of hallucinations in the population. Social Psychiatry and Psychiatric Epidemiology, 26, 287-92. https://doi.org/10.1007/BF00789221

van Bergen, R. S., \& Jehee, J. F. M. (2019). Probabilistic Representation in Human Visual Cortex Reflects Uncertainty in Serial Decisions. The Journal of Neuroscience, 39(41), 8164-8176. https://doi.org/10.1523/JNEUROSCI.3212-18.2019

Van Kerkoerle, T., Self, M. W., \& Roelfsema, P. R. (2017). Layer-specificity in the effects of attention and working memory on activity in primary visual cortex. Nature Communications, 8, 13804. https://doi.org/10.1038/ncomms13804

Wang, L., Metzak, P. D., \& Woodward, T. S. (2011). Aberrant connectivity during self-other source monitoring in schizophrenia. Schizophrenia Research, 125, 136-42. https://doi.org/10.1016/j.schres.2010.11.012

Waters, F. A. V., Badcock, J. C., Michie, P. T., \& Maybery, M. T. (2006). Auditory hallucinations in schizophrenia: Intrusive thoughts and forgotten memories. Cognitive Neuropsychiatry, 11(1), 65-83. https://doi.org/10.1080/13546800444000191

Waters, F., Barnby, J. M., \& Blom, J. D. (2021). Hallucination, imagery, dreaming: reassembling stimulus-independent perceptions based on Edmund Parish's classic misperception framework. Philosophical Transactions of the Royal Society B: Biological Sciences, 376(1817), 20190701. https://doi.org/10.1098/rstb.2019.0701

Waters, F., Collerton, D., Ffytche, D. H., Jardri, R., Pins, D., Dudley, R., ... Laroi, F. (2014). Visual hallucinations in the psychosis spectrum and comparative information from neurodegenerative disorders and eye disease. Schizophrenia Bulletin, 40, 233-45. https://doi.org/10.1093/schbul/sbu036

Wengler, K., Goldberg, A. T., Chahine, G., \& Horga, G. (2020). Distinct hierarchical alterations of 
intrinsic neural timescales account for different manifestations of psychosis. ELife, 9. https://doi.org/10.7554/eLife.56151

Whitford, T. J., Jack, B. N., Pearson, D., Griffiths, O., Luque, D., Harris, A. W. F., ... Le Pelley, M. E. (2017). Neurophysiological evidence of efference copies to inner speech. ELife, 6. https://doi.org/10.7554/eLife.28197

Winlove, C., Milton, F., Ranson, J., Fulford, J., MacKisack, M., Macpherson, F., \& Zeman, A. (2018). The neural correlates of visual imagery: a co-ordinate-based meta-analysis. Cortex, 105, 4-25. https://doi.org/10.1016/j.cortex.2017.12.014

Wittmann, M. K., Kolling, N., Faber, N. S., Scholl, J., Nelissen, N., \& Rushworth, M. F. S. (2016). SelfOther Mergence in the Frontal Cortex during Cooperation and Competition. Neuron, 91(2), 482-493. https://doi.org/10.1016/j.neuron.2016.06.022

Xie, S., Kaiser, D., \& Cichy, R. M. (2020). Visual Imagery and Perception Share Neural Representations in the Alpha Frequency Band. Current Biology. https://doi.org/10.1016/j.cub.2020.04.074

Yanagi, M., Hosomi, F., Kawakubo, Y., Tsuchiya, A., Ozaki, S., \& Shirakawa, O. (2020). A decrease in spontaneous activity in medial prefrontal cortex is associated with sustained hallucinations in chronic schizophrenia: An NIRS study. Scientific Reports, 10(1), 1-7. https://doi.org/10.1038/s41598-020-66560-2

Zeidman, P., Mullally, S. L., \& Maguire, E. A. (2015). Constructing, perceiving, and maintaining scenes: Hippocampal activity and connectivity. Cerebral Cortex, 25(10), 3836-3855. https://doi.org/10.1093/cercor/bhu266

Zeman, A., Milton, F., Della Sala, S., Dewar, M., Frayling, T., Gaddum, J., ... Winlove, C. (2020). Phantasia-The psychological significance of lifelong visual imagery vividness extremes. Cortex, 130, 426-440. https://doi.org/10.1016/j.cortex.2020.04.003

Zmigrod, L., Garrison, J. R., Carr, J., \& Simons, J. S. (2016, October 1). The neural mechanisms of hallucinations: A quantitative meta-analysis of neuroimaging studies. Neuroscience and Biobehavioral Reviews, 69, 113-123. https://doi.org/10.1016/j.neubiorev.2016.05.037 
